\title{
Expectancy Value Theory as a Tool to Explore Teacher Beliefs and Motivations in Elementary Mathematics Instruction
}

\author{
Corinne Thatcher Day*
}

\author{
Received \\ Revised \\ Accepted \\ 21 May 2020 \\ 6 October 2020 \\ 1 December 2020 \\ 10.26822 /iejee.2021.182
}

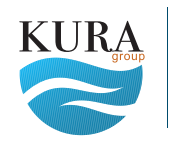

Copyright C

WWw.iejee.com

ISSN: 1307-9298

(C) 2020 Published by KURA Education \& Publishing. This is an open access article under the CC BY- NC- ND license. (https://creativecommons. org/licenses/by/4.0/)

\begin{abstract}
This case study explores the utility of Expectancy Value Theory (EVT) as a framework for studying elementary teachers' beliefs and motivations with respect to reformed mathematics instruction. A model for coding and evaluating qualitative data using EVT is proposed and illustrated using interviews with three primary school teachers in an urban school district in the United States. Results from the study indicate that anticipated costs associated with reform instruction, including not covering required content and not meeting district benchmarks, function as strong inhibitors to reform, even among teachers who value reform instruction, who exhibit a strong sense of self-efficacy, and who believe in their students' capacities to succeed with reform-oriented instruction.
\end{abstract}

\author{
Keywords: \\ Elementary School Teachers, Expectancy Value Theory, \\ Mathematios Instruction, Teacher Attitudes, \\ Teacher Motivation
}

\section{Introduction}

In the 1980s the mathematics education community in the United States, spearheaded by the National Council of Teachers of Mathematics (NCTM), initiated a new era of reform efforts motivated by the constructivist belief that children learn mathematics best through active and collaborative engagement in problem solving tasks (NCTM, 1980; 1989). Citing best practices in math instruction from around the world, NCTM has promoted a more studentcentered approach to mathematics teaching and learning than has traditionally characterized U.S. classrooms (2000; 2014). Despite over three decades of calls for change, however, most math instruction in the United States remains mired in long-eschewed behaviorist approaches to education in which teachers present step-by-step instruction before turning students over to plug and chug through sets of prescribed practice problems (NCTM, 2014). Even teachers with extensive training in reform-based practices often struggle to faithfully implement reform instruction (Louie, 2017a; 2017b). 
Numerous reasons for this struggle are evident in the mathematics education literature, including disciplinary and professional constraints on educators (Smith, 2012; Stemhagen, 2011; Warfield et al., 2005; Webel \& Platt, 2015; Windschitl, 2002; Yurekli et al., 2020) as well as educators' efficacy beliefs about self and students (Abrami et al., 2004; Cross Francis, 2015; Rousseau, 2004; Thompson, 1984; Warfield et al., 2005; Yurekli et al., 2020). A complex interplay between internal beliefs and external constraints influences teachers' instructional decisions. Beliefs also vary depending on contexts, "so to examine beliefs without paying close attention to the unfolding of teachers' practices through interaction within contexts would be methodologically and analytically inappropriate" (Cross Francis et al., 2015, p. 338). The interaction between beliefs and contexts requires a theoretical model that extends beyond teacher beliefs and enables researchers to capture other factors influencing educators' instructional choices.

Expectancy Value Theory, originally proposed by Wigfield and Eccles (2000) to study academic achievement among students and adapted for use among teachers by Abrami et al. (2004), is a promising model for studying the influences on teachers' instructional decision making because it encompasses both beliefs and the anticipated costs associated with making particular decisions within particular contexts. Using Expectancy Value Theory (EVT) as a theoretical framework for understanding teachers' instructional practices, the present study sought to explore the interactions between teachers' beliefs and their professional contexts to better understand their instructional decisions with respect to mathematics education reform.

\section{Contrasting Instructional Models}

The beliefs that mathematics educators hold and the instructional decisions that they make can be characterized along a continuum from traditional to reform instruction, with many teachers' beliefs and decisions reflecting a blend of these two instructional models (Raymond, 1997). Traditional instruction is characterized by teacher who provide explicit, step-by-step instruction on how to solve specific mathematical problems. As Goldsmith and Shifter (1997) describe, "Traditional mathematics instruction is grounded in the belief that students learn by receiving clear, comprehensible, and correct information about mathematical procedures [...] Classroom instruction is organized around the transfer of information from knowledgeable teacher to uninformed student" (pp. 22-23).
On the other end of the continuum, reform instruction is characterized by students actively engaging in problem-solving activities facilitated and designed by teachers who take into account students' prior knowledge, current interests, and cognitive development during lesson planning and implementation. This definition was derived from NCTM's description of high-quality math instruction, in which "mathematics lessons should be centered on engaging students in solving and discussing tasks that promote reasoning and problem solving" and in which teachers should "plan lessons to prompt student interactions and discourse, with the goal of helping students to make sense of mathematical concepts and procedures" (2014, p. 10). NCTM also advocates for teachers to "elicit and use evidence of student thinking" such that they can "assess progress toward mathematical understanding and to adjust instruction continually in ways that support and extend learning" (2014, p. 10).

Promoting reform instruction that enables each and every student to succeed in mathematics is a primary goal of NCTM, whose principals are advocated in the school district that is the subject of this study. Yet upon entering any given K-5 classroom in the study district, an observer is unlikely to witness instruction that falls solidly on the reform end of the instructional continuum and will instead encounter many classrooms in which traditional instruction dominates. As a teacher educator whose pre-service teachers student teach in the district, the researcher wanted to explore the reasons why in-service educators in the district are not implementing reform recommendations to a greater degree.

\section{Study Purpose and Research Questions}

The present study contributes to the research literature on teachers' beliefs by exploring the interactions between teachers' beliefs and their professional contexts in relation to their instructional decision-making. Whereas many studies have analyzed mathematios teachers' beliefs, only a few have attempted specifically to incorporate beliefs and institutional contexts within the same model (e.g, Yurekli et al., 2020). This study adds to the existing literature by analyzing the interplay between teachers' personal beliefs and the institutional realities that motivate their instructional choices. In so doing, it responds to Watt and Richardson's (2015) call to "marry" beliefs research with research on motivation in a way that "systematically fosters theoretical crossfertilization and hybridization" (p. 203). 
Specifically, the following research questions were addressed:

- When asked to explain why they feel that their math instruction falls short of reform recommendations, what reasons do K-5 teachers provide?

- Do teachers' expressed reasons for falling short of reform align with the three domains of Expectancy Value Theory?

- Which of the three domains appears to weigh most heavily in the teachers' instructional decision-making?

- How might these domains be delineated within a conceptual model to best reflect the efficacy beliefs, values, and costs associated with reform instruction?

Going into the study, it was hypothesized that the participating teachers would believe their job to be to "teach to the test." While this might be viewed as a lamentable outcome of the high-stakes testing environment in which teachers find themselves in the United States, it was nevertheless anticipated that the teachers would subscribe to the importance of procedural fluency and test preparation. Such beliefs permeate the literature and also emerged as a concern among teachers in the study district who had completed an informal survey on reform instruction the year before the present study commenced. Testing was clearly on teachers' minds, but in order to understand in what ways it might impact their instruction, further exploration was needed.

\section{Conceptual Framework}

Expectancy Value Theory (EVT) was chosen as the conceptual framework for this study because of its capacity to capture multiple decision-making factors within a single framework. According to EVT, an individual's decision-making process involves a cost-benefit analysis weighing three primary considerations: the expectancy of succeeding in a particular task, the personal value attributed to the task, and anticipated costs associated with pursuing the task (Abrami et al., 2004; Wigfield \& Eccles, 2000). In their quantitative study of cooperative learning $(\mathrm{CL})$ in Canada, Abrami et al. (2004) found that the three domains of EVT (expectancy of success, personal values, and associated costs) aligned well with survey items chosen by teachers to explain their use or nonuse of CL. Their findings suggest that EVT can serve as a powerful explanatory model for illuminating the complex relationship between teacher's beliefs and practices. In their study, seven of the ten significant predictors of $\mathrm{CL}$ implementation reflected the expectancy of success component of the framework, with the most common factors relating to expectations of students' capabilities. Only one cost item proved to be significant-preparation time to plan for $\mathrm{CL}$-and two value items were significant, including alignment between $C L$ and a teacher's educational philosophy. While the Abrami et al. (2004) study did not focus on math instruction specifically, it echoes findings from math education research, where similar relationships have been identified between teachers' beliefs about students and their use of reform instructional practices (Rousseau, 2004; Thompson, 1984; Warfield et al., 2005; Yurekli et al., 2020). Further research utilizing the EVT framework is warranted both to confirm its utility in evaluating the impact of teachers' beliefs and motivations on their instructional choices as well as to explore whether expectancy of success remains the most salient decision-making factor in other educational contexts.

\section{Methods}

\section{Context and Participants}

The study took place in an urban public school district in the northwestern United States. Reform instruction is emphasized by the district's K-5 math coach, a member of the board of directors for the NCTM affiliate in the state. Three K-5 teachers were recruited for the study from a sample of teachers who had completed a voluntary electronic survey emailed to primary school teachers in the district. Forty-five teachers completed the survey, representing approximately one in eight $\mathrm{K}-5$ teachers in the district. The survey asked teachers to identify the frequency with which they utilized ten reform-oriented mathematics instructional practices and to list factors that supported and inhibited their efforts to use these practices. The participants were chosen because their responses reflected the overall sentiments of the teachers who completed the survey. Each participant, like many of the other respondents, indicated on their survey that they utilized several of the ten reform practices but that they were not able to use them to the extent that they would like to due to three main inhibiting factors: the need to cover a large amount of content; the need to ensure students learn standard mathematical procedures; and the need to prepare students for standardized tests.

Each participant taught at a different grade level and worked at a different school in the district. A 
kindergarten teacher, a second-grade teacher, and a fifth-grade teacher were selected for the study because of the testing requirements within the district. Beginning in second grade, students take state-mandated standardized tests in both the fall and spring. A kindergarten teacher is working with students who are several years removed from the state-mandated testing requirements (although they do engage in district benchmark testing); a secondgrade teacher is instructing students during the first year in which they engage in state testing; and a fifthgrade teacher is working with students who are well accustomed to the annual state tests.

Mrs. P, the kindergarten teacher, had 37 years of teaching experience at the time of the study. For most of her career, she had taught in self-contained special education classrooms but had been teaching in regular education classrooms for the past eight years. Ms. S, the second-grade teacher, had been teaching pre-school and early primary grades for 22 years at the time of the study. Mr. C, the fifth-grade teacher, was in his fifth year of teaching in the same grade level in the same school.

\section{Data Collection and Analysis Procedures}

Audio-recorded, one-on-one, semi-structured interview were conducted with each of the three teachers. The recordings were transcribed and imported into NVivo12 for coding using an a prioricoding scheme designed to organize the teachers' responses according to the three domains of Expectancy Value Theory. The section below describes the development of the preliminary conceptual model utilized during the coding process. The researcher remained open to reorganizing the model and to creating new nodes if themes emerged from the data that did not align with the existing domains and constructs. Each transcript was coded and then revisited several weeks later to refine the analysis, at which point several of the constructs within the preliminary model were renamed and reorganized. A codebook is included in the Appendix for reference.

For triangulation, a word frequency query was conducted to explore whether particular words or phrases permeated the interview data. The findings from the coding analysis were further compared against the survey responses that had been submitted by each teacher during the prior school year as well as against researcher memos recorded before and after each interview. Member checks were conducted to ensure that the teachers' responses were accurately interpreted. Each teacher was provided with a draft of this article and given time to provide feedback before the draft was finalized.

\section{Preliminary Conceptual Model}

In order to utilize EVT as a framework for this study, each of the three domains (expectancy of success, personal values, and anticipated costs) were operationalized in terms of the literature on mathematics teachers' beliefs and practices. Figure 1 presents a visual model of the relationship between teachers' beliefs and practices through the lens of EVT. Teachers' beliefs, values, and motivations were situated within the model in such a way as to indicate their relationship to instructional practice-reform or traditional-as

\section{Figure 1}

Preliminary Conceptual Model

\section{Expectancy Value Theory}

\section{Expectancy of Success}

$\begin{array}{cc}\begin{array}{c}\text { High Self-Efficacy } \\ \text { and Autonomy }\end{array} & \begin{array}{c}\text { Low Self-Efficacy } \\ \text { and Autonomy }\end{array} \\ \begin{array}{c}\text { High Expectations } \\ \text { of Students }\end{array} & \begin{array}{c}\text { Low Expectation } \\ \text { of Students }\end{array} \\ \begin{array}{c}\text { Strong Support } \\ \text { Network }\end{array} & \begin{array}{c}\text { Weak Support } \\ \text { Network }\end{array} \\ \text { Reform } & \begin{array}{c}\text { Traditional } \\ \text { Instruction }\end{array} \\ \text { Instruction } & \text { intion }\end{array}$

Personal Values

$\begin{array}{cc}\begin{array}{c}\text { Math Knowledge } \\ \text { is Constructed }\end{array} & \begin{array}{c}\text { Math Knowledge is } \\ \text { Transmitted }\end{array} \\ \begin{array}{c}\text { Student Autonomy } \\ \text { is Important }\end{array} & \begin{array}{c}\text { Teacher Authority is } \\ \text { Important }\end{array} \\ \text { Growth Mindset } & \text { Fixed Mindset }\end{array}$

\author{
Traditional \\ Instruction
}

\section{Anticipated Costs}

$\begin{array}{cc}\begin{array}{c}\text { Lack of Student } \\ \text { Understanding }\end{array} & \begin{array}{c}\text { Not Covering } \\ \text { Curriculum Content }\end{array} \\ \begin{array}{c}\text { Lack of Student } \\ \text { Autonomy }\end{array} & \begin{array}{c}\text { Lack of Success on } \\ \text { Standardized Tests }\end{array} \\ \begin{array}{c}\text { Lack of Belief- } \\ \text { Practice Alignment }\end{array} & \begin{array}{r}\text { Lack of Procedural } \\ \text { Fluency }\end{array}\end{array}$

Reform
Instruction
Traditional Instruction 
identified in the literature. Each of the model's three domains are described in more detail in the sections that follow.

\section{Expectancy of Success}

Teachers' beliefs about students and about themselves are reflected within the expectancy of success component of the EVT framework. Some teachers hold low expectations of their students, believing that their students are incapable of engaging successfully in reform-oriented instruction (Cross Francis, 2015; Gill \& Hoffman, 2009; Rousseau, 2004; Thompson, 1984; Warfield et al., 2005; Wilkins, 2008; Yurekli et al., 2020). Other teachers do not feel capable of enacting successful reform instruction or do not feel that they have the authority to diverge from the discipline's long history of direct instruction (Cooney \& Shealy, 1997; Cross Francis, 2015; Warfield et al., 2005; Webel \& Platt, 2015). Teachers who do successfully enact reform instruction hold higher expectations of their students and of themselves and often enjoy significant institutional and/or peer support (Hart, 2002; Lloyd, 2002; Louie, 2017a, b; Ren \& Smith, 2018; Smith, 2012; Thompson, 1984; Wilson \& Cooney, 2002).

\section{Personal Values}

Personal values are also associated with teachers' use or non-use of reform instruction. Teachers who harbor relativistic mindsets, valuing personal growth and development, are often found to be more successful at implementing reform instruction than teachers who harbor dualistic mindsets, favoring constancy and stability (Cooney \& Shealy, 1997; Smith, 2012). In contemporary jargon, a relativistic mindset is akin to a "growth" mindset and a dualistic mindset akin to a "fixed" mindset (Boaler, 2016). Teachers with dualistic or fixed mindsets tend also to view the discipline of mathematics itself as fixed: as a set of procedures and operations to be transmitted and memorized as opposed to a tool for productive thought and inquiry. Consequently, they interpret their role as one of control over classroom knowledge. In contrast, teachers with relativistic mindsets often assume a role of supporting student autonomy and sense making (Boaler \& Staples, 2008; Raymond, 1997; Stipek et al., 2001)

\section{Anticipated Costs}

Other reasons cited in the literature for not implementing reform-oriented practices include disciplinary and professional constraints such as the need to keep up with district pacing guides, the need to prepare students for standardized testing, and the need to ensure fluency with standard mathematical algorithms (Raymond, 1997; Smith,
2012; Stemhagen, 2011; Warfield et al., 2005; Webel \& Platt, 2015; Windschitl, 2002; Yurekli et al., 2020). These constraints reflect perceived costs that might be incurred in exchanging direct instruction for reformoriented practices. On the other hand, teachers who are unwilling to sacrifice students' understanding of mathematics or to belie their own personal beliefs about the power of reform instruction-regardless of whether curriculum mandates are met, standard procedures are mastered, or standardized test scores are high-are more likely to implement reform recommendations (Abrami et al., 2004; Smith, 2012; Boaler \& Staples, 2008). While the constructs within the anticipated costs domain do not represent clear binaries as they do in the other two domains, the set of constructs associated with reform instruction serves as a collective binary when juxtaposed against those associated with traditional instruction: on the one side, priorities associated with students are the focus, while on the other side, priorities passed down by administrators and other higher-level authorities are the focus.

\section{Student Autonomy: Tentative Placement Within the Preliminary Model}

Student autonomy appears twice in the preliminary model because the way this construct is discussed in the literature does not clearly indicate to which domain it best belongs. Student autonomy appears relevant to both personal values and anticipated costs. For example, in Smith (2012), "Mrs. Zatechka believed her main job as a classroom teacher was to teach students to think" (p. 319). Mrs. Zatechka did not allow the district curriculum to govern her instruction, and this was both because she valued student autonomy and because she was unwilling to pay the cost of giving up this autonomy in favor of following the curriculum in lock step. Ultimately, an optimal structure for a model of math teacher's beliefs and motivations based on EVT was determined via the research process, as described in the results section.

\section{Results}

\section{Overview}

For the teachers in this study, a desire to "teach to the test" was not in fact a factor in their instructional decision-making. Nor did a lack of will, desire, or selfefficacy appear to be inhibitors to reform instruction, in contrast to the findings of Abrami et al. (2004). Instead, the teachers all expressed strong reform-oriented beliefs but felt constrained by district mandates, such as trimester reporting goals tied to state and national standards. All of the teachers, especially the early primary teachers, shared a desire for their students to 
truly understand the mathematics they were learning, and they each expressed confidence in their students' abilities to do so under the right instructional conditions. None of the teachers expressed any statements reflecting personal values associated with traditional math instruction in the conceptual framework. To the contrary, they made many statements aligned with the tenets of reform instruction. In the sections that follow, the research outcomes are organized according to the three domains of the EVT model.

\section{Anticipated Costs}

\section{Not Covering Curriculum Content}

All three teachers in the study shared an overt concern for a lack of sufficient time to teach mathematics in a more reformed manner. Tellingly, "time" also emerged as the third most frequent word in the word query. The other 20 most frequent words were those that might appear in any conversation about math education such as math, think, and kids. All of the statements made with respect to time were related to the anticipated cost of not covering curriculum content prescribed by the district. Several different reasons were provided by the teachers for struggling to find time for reform instruction while still keeping pace with the curriculum. To accommodate these reasons, three sub nodes were created within the node not covering curriculum content in order to reflect the variety of responses: too much content, time limited by daily schedule, and time lost to testing.

Too much content was the most salient category in the entire data set. Most of the statements made by Mrs. P and Ms. S with respect to content coverage fell under this sub node. Throughout her interview, Ms. S returned to her concerns over the fast pace at which she finds herself moving through content in order to keep up with the district's proficiency rubrics, which are organized according to trimester reporting goals:

So if, for instance, even now in second grade, you know, we're moving on, we're doing three digit addition and we're moving on. Well if you still don't have your math facts that's a problem being able to continue in that math. Well, can I hold back and say, "Okay, let's hold back, let's all get this under..." I don't have that luxury. [...] that curriculum has to march on.

Later in the interview, she circled back to the same concern:

You know, do I have most kids that can't make a ten? Oh gosh, now I'm really going to have to spend way more time on that. Curriculum demands I need to get on because I gotta cover those other skills.
Mrs. P shared similar sentiments with respect to time:

\begin{abstract}
... the pacing guide and the timeliness of being able to report on this standard at this point, and then the next trimester we add on to it but we have to report on what we didn't finish reporting on, continue reporting on it. And so by the time you're at the end of the year, those kids that are still doing concrete, they've kind of missed out on the new stuff that's coming because you're still shoring up those cheese holes, if you think about Swiss cheese and all the little holes. I try to teach so we don't have holes, but it's the nature of how quick we maybe go.
\end{abstract}

Several of Mrs. P's comments with respect to content coverage also touched on the short amount of instructional time for math due to an abbreviated school day (in the study school district, $\mathrm{K}$-3 students are released 45 minutes earlier than older students) as well as to other curriculum requirements and to the many transition times during the day such as specials, lunch, and recess. Ms. S likewise pointed out the shortened school day as problematic, indicating time limited by daily schedule.

For Mr. C, extra planning time was the primary concern with respect to time, although too much content came in second. An extra node by this title was added to the conceptual model to capture responses such as the following:

I don't know if I'm necessarily limited on what I can do. I think the struggle of mine is just finding time to make sure that my lessons are as engaging or complete as, or as whole as l'd like them to be. It comes down to a time thing. I mean, you know, it's the grading, the planning...

Mrs. P also expressed a need for more planning time in her interview. In lamenting her inability to incorporate thematic units into her teaching, she articulated, "it's really hard to find the time to fit that in and logistically have the materials ready for 20 kids in a classroom."

All three teachers also shared a concern over time lost to testing. The early primary teachers were not concerned at all about "teaching to the test" but rather were concerned that time taken up by testing limited their ability to teach for understanding. Ms. S was especially frustrated by the testing requirements in the district. She expounded, "I just question all the testing that we do back to back to back to back. Now I'm three weeks into school and I've hardly taught anything because my days are spent testing."

Time lost to testing and time rushed to cover required content also emerged as themes in the earlier surveys completed by the two early primary teachers. In their surveys, Mrs. P and Ms. S both left comments lamenting the limitations on their time due to the fast pace of the curriculum and the need to use instructional time 
for testing. In response to an open-ended question prompting teachers to explain some of the factors that inhibit reform instruction, Ms. S wrote, "The lack of time is a huge issue in allowing students to enjoy student centered learning. Curriculum demands as well as testing demands take precedence over best practices." Mrs. P affirmed, "Just time...time to provide quality instruction and learning opportunities. Much of the year feels rushed and teaching time disappears for [benchmark] testing." My researcher memos corroborated this concern with time. After the interview with Ms. S, I recorded the following observation: "Overall I got the impression that Ms. S understands the tenets of student-centered teaching well and would like to teach that way but feels the district's pacing is too fast and testing takes away too much time."

\section{Lack of Procedural Fluency}

During her interview, Ms. S discussed the overwhelming number of standard algorithms that must be covered in second grade. When asked what she meant by standard algorithms, Ms. S described the many alternative addition and subtraction strategies incorporated into the mathematics content standards adopted by most U.S. states (for example, using association to make a 10 when adding $8+3$ ). She did not feel she had the flexibility to allow students to use and master only those strategies that made the most sense to them but rather needed to cover all of the potential methods since they are incorporated into the district's proficiency rubrics. She opined, "We want them to be able to think conceptually, but in second grade, at this point in second grade, sometimes it is easier to stick with one strategy for a while, and then incorporate another one. You see we have to do it so quickly because we're trying to get that curriculum covered." The passage of text associated with this exchange was double-coded as too much content because it expressed a concern over curriculum requirements rather than with procedures per se. Ms. $S$ was concerned that the sheer number of strategies she had to teach her students was inhibiting their understanding of those strategies that might be the most useful for them in their learning and growth.

\section{Lack of Success on Standardized Tests}

Much like Ms. S's concerns over procedures, Ms. S's and Mrs. P's comments with respect to standardized testing had less to do with testing per se and more to do with time lost to testing, which is associated with not covering curriculum content more so than lack of success on standardized tests (as described above).
Mr. C made the greatest number of statements with respect to testing. He does want his students to feel successful on the state-mandated tests they take each year. He was clear to articulate, however, that his concern lies with his students' sense of accomplishment rather than with school rankings or his own job security: "it boils down to the students being successful and them knowing that it was a successful year in what they did to get there." Mr. C did not indicate that test preparation should be a key focus of his instruction but rather agreed that meaningful mathematical tasks would support the strongest learning outcomes in his students.

\section{Lack of Student Understanding and Autonomy}

All three teachers shared a strong concern for their students' self-confidence and success in math. Mrs. P and Ms. S made a number of statements expressing a desire to have more instructional time to ensure conceptual understanding before moving on to more abstract or advanced concepts. Ms. S pointed out, "If you don't have any number sense, if you can't put groups together and take them apart, you are lost." Mrs. P noted, "We don't always feel like we have time. We need to learn to give ourselves permission to take the time to do it in the concrete manner before we move to representation, before we move to the abstract." Many of the statements shared in earlier sections that were double-coded as lack of time and too much content were in fact triple-coded as lack of student understanding. In essence, insufficient time to ensure student understanding due to curricular constraints is the primary sentiment arising from the interviews with these two teachers.

Ms. S also expressed frustration with having to introduce children to so many different strategies that she could not allow them to simply stick with the strategies that work best for them before having to teach them another, suggesting that a lack of student autonomy is of concern to her. She pointed out, "When you try to add in all those different ways to do something, sometimes it's not as beneficial as just saying, 'Let's do it this way, this works easiest for youyou're getting the answers correct this way."'

\section{Personal Values and Expectancy of Success}

Notably, none of the teachers exhibited a single personal value associated with traditional instruction in the conceptual model. Although they were not specifically prompted to describe their beliefs about students, the teachers nonetheless shared statements indicating that they believe in their students' abilities to succeed (growth mindset); that students need to build a strong conceptual foundation in math 
(mathematical knowledge is constructed); and that students should be able to work together and learn from one another. I renamed the node student autonomy is important to student interaction is important to capture the latter sentiment.

\section{Growth Mindset}

In discussing the role that standardized testing plays in his instruction, Mr. C commented,

first and foremost we want the kids to succeed and feel successful, and see their growth from fall to spring. And, you know, if they see that success and know the hard work, and kind of what they put into that, hopefully that would transpire to future years.

His primary concern lay not with achieving certain benchmarks for his own benefit or for that of the district-although he did admit to feeling pressure to have his students perform well-but rather for his students' self-confidence in mathematics. He believed that his students could experience significant growth in mathematics and he wanted them to believe the same about themselves; he viewed improvements in their tests scores from fall to spring as an opportunity to bolster this belief.

Both Ms. S and Mrs. P expressed utilizing flexible grouping as opposed to fixed-ability grouping in their classrooms, indicating that they do not track students into "low" or "advanced" levels that might inhibit students' development or self-perceptions. For example, Ms. S explained,

Well if I have two or three that I'm like, you know they've mastered that, let's move them on, let's pull back somebody who hasn't. So you see we're constantly making those groups fluid depending on what her needs are, what mine are, who's mastered, who hasn't

Mrs. P similarly affirmed, "they would be flexible groups because some kids get certain concepts in some areas as opposed to others. So they wouldn't be stationary groups, or have the same kids all the time." In her earlier survey, she alluded to a belief in every student's potential to succeed: "Instruction needs to meet the learner where he or she is at and move each child forward to reach their individual potential."

\section{Student Interaction is Important}

In both her interview as well as her earlier survey, Ms. S expressed confidence in her students' ability to learn from one another and not just from the teacher. When discussing instructional strategies she wish she had more time to implement, she related a scenario in which a child with whom she had been working one-on-one to convey a concept was finally able to comprehend the concept when another child verbalized his thinking during a Number Talk. She concluded, "Kids are powerful teachers to each other." In her survey, she wrote, "It is critical that students have student-centered activities to enhance their learning of math concepts, as well as being able to collaborate with their classmates."

\section{Math Knowledge is Constructed}

Both Ms. S and Mrs. P underscored the importance of building a solid conceptual foundation before moving into abstract representations and concepts in mathematics. Ms. S emphasized the importance of getting K-2 students "grounded in number sense" before presenting students with procedures. Mrs. P stated, "when you're teaching K-1-2, we need to have time to build those concepts through concrete experiences."

\section{Revised Conceptual Framework}

Figure 2 depicts the results of the data analysis in a revised conceptual framework. In the second iteration of coding, three of the original nodes were renamed and an additional node was created in order to accurately reflect the teachers' sentiments. The term "autonomy" was removed from high self-efficacy and autonomy and from low self-efficacy and autonomy because this wording conflicted with the teachers' interview statements. While the teachers all expressed a strong sense of self-efficacy, they did not feel they had the autonomy to deviate from their district's benchmark standards; hence, statements associated with self-efficacy could not be accurately coded using this node if the phrase "and autonomy" remained in the label.

Initially, the word autonomy was intended to capture findings from the literature suggesting that some teachers do not feel they have the autonomy or authority to deviate from teaching math in traditional ways, which is typically associated with low selfefficacy (Cooney \& Shealy, 1997; Cross Francis, 2015; Warfield et al., 2005; Webel \& Platt, 2015). Ultimately, this finding can be captured by the term self-efficacy alone (without "and autonomy" tacked on) and/ or within the personal values domain under the node math knowledge is transmitted depending on whether a teacher articulates a personal lack of confidence in deviating from traditional instruction (a self-efficacy belief) or whether they feel that it is simply not acceptable to teach math in a more openended manner (a personal value).

As noted above, the additional node extra planning time was created to capture statements regarding 
a lack of sufficient planning time. Student autonomy is important was renamed student interaction is important since this better captures the interview data and better pairs with the binary in the personal values domain teacher authority is important because it suggests that students' knowledge and skills are valued in a classroom and not just those of the teacher. The new title also distinguishes it more clearly from lack of student autonomy in the anticipated costs domain, which refers to statements made regarding student choice in problem-solving approaches.

Nodes in bold font in the revised conceptual framework indicate the most frequently coded nodes while nodes in grey indicate nodes under which no data was coded. All of the most oftrepeated concerns among the three teachers fell under the domain of anticipated costs, while minimal evidence emerged from the interviews suggesting that the teachers held values or expectancy beliefs associated with traditional instruction. Table 1 shows a quantitative summary of the coding outcomes, which informed the visual overlays on the concept map. The highest number of significant passages of text fell within the node not covering curriculum content. In the second cycle of coding, this node was split into three sub nodes - too much content, time limited by daily schedule, and time lost to testing — to distinguish among comments that focused on various constraints on time. It is perhaps fitting that the anticipated costs domain became imbalanced during the coding process, causing asymmetry in the model: indeed, there is clearly an imbalance in many public school systems that causes so many teachers to remain firmly on the traditional end of the instructional continuum despite decades of calls for reform.

\section{Discussion}

\section{Why Instruction Falls Short of Reform Recommendations}

Concerns related to content coverage, procedural fluency, and standardized testing among the three teachers interviewed for this research project all

Table 1

Quantitative Summary of Coded Interview Data

\begin{tabular}{|c|c|c|c|c|}
\hline Node & Total Count & Mrs. P & Ms. S & Mr. C \\
\hline \multicolumn{5}{|l|}{ Expectancy of Success: } \\
\hline High Self-Efficacy & 7 & 3 & 3 & 1 \\
\hline High Expectations of Student & 7 & 3 & 4 & \\
\hline Strong Support Network & 5 & 1 & 3 & 1 \\
\hline \multicolumn{5}{|l|}{ Low Self-Efficacy } \\
\hline Low Expectations of Students & 1 & & 1 & \\
\hline Weak Support Network & 3 & 3 & & \\
\hline \multicolumn{5}{|l|}{ Personal Values: } \\
\hline Math Knowledge is Constructed & 5 & 3 & 2 & \\
\hline Student Interaction is Important & 4 & & 4 & \\
\hline Growth Mindset & 6 & 3 & 2 & 1 \\
\hline \multicolumn{5}{|l|}{ Math Knowledge is Transmitted } \\
\hline \multicolumn{5}{|l|}{ Teacher Authority is Important } \\
\hline \multicolumn{5}{|l|}{ Fixed Mindset } \\
\hline \multicolumn{5}{|l|}{ Anticipated Costs: } \\
\hline Lack of Student Understanding & 16 & 4 & 11 & 1 \\
\hline \multicolumn{5}{|l|}{ Lack of Student Autonomy } \\
\hline Lack of Belief-Practice Alignment & 8 & 1 & 4 & 3 \\
\hline Lack of Success on Standardized Tests & 5 & & & 5 \\
\hline Lack of Procedural Fluency & 1 & & 1 & \\
\hline Extra Planning Time & 8 & 2 & & 8 \\
\hline \multicolumn{5}{|l|}{ Not Covering Curriculum Content } \\
\hline Too Much Content & 19 & 5 & 11 & 3 \\
\hline Time Limited by Daily Schedule & 4 & 2 & 1 & 1 \\
\hline Time Lost to Testing & 4 & 1 & 2 & 1 \\
\hline
\end{tabular}


Figure 2

Revised Conceptual Model

\section{Expectancy Value Theory}

Expectancy of Success

$\begin{array}{cc}\text { High Self-Efficacy } & \text { Low Self-Efficacy } \\ \begin{array}{c}\text { High Expectations } \\ \text { of Students }\end{array} & \begin{array}{c}\text { Low Expectations } \\ \text { of Students }\end{array} \\ \begin{array}{c}\text { Strong Support } \\ \text { Network }\end{array} & \begin{array}{c}\text { Weak Support } \\ \text { Network }\end{array} \\ \begin{array}{c}\text { Reform } \\ \text { Instruction }\end{array} & \begin{array}{c}\text { Traditional } \\ \text { Instruction }\end{array}\end{array}$

Personal Values

$\begin{gathered}\text { Math Knowledge } \\ \text { is Constructed }\end{gathered}$
$\begin{gathered}\text { Math Knowledge is } \\ \text { Transmitted }\end{gathered}$
$\begin{gathered}\text { Student Interaction } \\ \text { is Important }\end{gathered}$
$\begin{gathered}\text { Teacher Authority is } \\ \text { Important }\end{gathered}$
Growth Mindset $\quad$ Fixed Mindset

Reform Instruction

\section{Traditional \\ Instruction}

\section{Anticipated Costs}

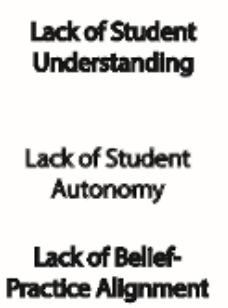

Reform Instruction
Not Covering

Curriculum Content

Lack of Success on Standardized Tests

Lack of Procedural

Fluency

Time

\section{Traditional}

Instruction
Extra Planning

coalesced around a single shared theme: time. None of the teachers were explicitly concerned with test preparation or procedural fluency per se. The kindergarten and second-grade teachers both felt that they did not have sufficient time to cover all of the required content included in their district's benchmarks in the hands-on way most meaningful to young learners. They felt that testing took up too much instructional time, compounding the struggle to provide adequate time to learn concepts on a conceptual level. The fifth-grade teacher, while more sympathetic to the benefits of standardized testing, also felt that testing time frames impinged on his ability to map out his curriculum in a more optimal manner; end-of-year testing occurs in April, forcing certain concepts to be covered more than a month before the school year comes to a close. He also felt that his school day did not include enough time for him to plan for more robust math instruction.

While Abrami et al. (2004) found the expectancy of success component of EVT to be the most significant predictor of using or not using cooperative learning -in their study, teachers who did not use CL reported low student expectations- in this study the cost construct seemed to weigh most heavily on the teachers' instructional choices. All four of the most salient nodes in the interview data fell within this construct. The teachers in this study did not appear to lack selfefficacy or a belief in their students' abilities to engage in reform instruction. To the contrary, they believed that students learn best from hands-on experiences and student-to-student interaction and they expressed concern over having to limit these practices. The cost of students not fully understanding the mathematics they are supposed to be learning was of great concern

to these teachers. However, this cost was outweighed by the time cost associated with implementing reform instruction and the need to meet certain benchmarks by certain time points during the school year. All three of the teachers reported having insufficient instructional and/or planning time to maximize their students' understanding of mathematics, at least not without sacrificing coverage of the content included in the district's proficiency scales.

\section{Using Expectancy Value Theory to Study Instructional Decision-Making}

In addition to exploring reasons why K-5 teachers find it difficult to implement math instruction that lies firmly on the reform end of the instructional continuum, this study sought to investigate the use of Expectancy Value Theory to frame research on teachers' beliefs and practices. The EVT framework proved to be an extremely helpful and relevant tool for doing so. All salient remarks made by the teachers during their interviews aligned well with one or more of the constructs embedded in the framework, much as Abrami et al. (2004) found in their quantitative study, which greatly facilitated the coding process. With adjustments made during data analysis, the EVT framework accurately captured both the personal and contextual factors influencing the teachers' instructional decisions.

The different findings arising from the present study and from Abrami et al. (2004) suggest that variables impacting instructional decision-making vary from context to context and that supporting reform instruction requires localized rather than one-sizefits-all approaches. Other educational researchers 
and those responsible for generating professional development opportunities might adapt the EVT framework developed for this study to identify the variables most salient to the contexts within which they are working in order to tailor reform efforts to the needs of the teachers in their districts. Teachers holding low expectations of students and disbelieving that mathematical knowledge can be constructed would require an entirely different form of professional development than teachers who believe in the abilities of their students to construct their own knowledge but who feel constrained by other factors. Survey items or focus group questions could be developed to capture teachers' sentiments with respect to the domains and constructs embedded in the model-much as Abrami et al. (2004) did for their study-to inform decisions associated not just with professional development but also with curricula, scheduling, and other factors that impact teachers' day-to-day instruction.

\section{Implications for Reform}

Although the findings from Abrami et al. (2004) indicate that expectancy of success is important-a teacher that does expect to succeed with reform instruction will not use it-the present study suggests that reform values may not be sufficient to promulgate meaningful reform. As evidenced by the concept map in Figure 2, a majority of the interview data indicate that the teachers in the study would be expected to engage in reformed math instruction based on the alignment of their values and expectancy beliefs with reform-oriented characteristics identified in the literature; however, the teachers all felt constrained in their ability to do so.

An important finding from this study is that even when teachers hold expectancy beliefs and personal values in line with reform instruction, school contexts may nonetheless inhibit their ability to implement reform practices. The teachers in this study are not teachers who are making excuses based on low self-efficacy or low expectations of their students, as teachers in other studies have expressed (Abrami et al., 2004; Rousseau, 2004; Thompson, 1984; Warfield et al., 2005). To the contrary, all three teachers exhibited confidence in their abilities to teach students for understandinggiven the freedom to do so-and articulated a clear understanding of the reform instruction advocated by NCTM. In their interviews, each teacher alluded to one or more best practices such as flexible grouping, students learning from students, using concrete representations to build conceptual understanding, and creating coherent lessons that address whole concepts and not just procedures. They reported using many of these practices themselves-but not to the extent that they would like to.

\section{Areas for Future Research}

The findings raise important questions for further research. First and foremost, it is imperative to continue to explore the role that professional duties and obligations play in limiting teachers' ability to implement reform recommendations. Many studies have suggested that high expectations of students and strong self-efficacy are characteristics that lend themselves to more reformed instruction (Abrami et al., 2004; Smith, 2012; Stipek et al., 2001; Warfield et al., 2005). However, the teachers in the present study expressed such enabling beliefs but nonetheless felt constrained in their practice, as other researchers have also found (Stemhagen, 2011; Webel \& Platt, 2015; Yurekli et al., 2020).

In one study, Smith (2012) found that a particular teacher was able to implement reform practices despite an institutional context that seemed to constrain the other teachers in the study. Unlike her peers, the reform teacher did not allow herself to feel limited by the district pacing and curriculum guides. Why did the teacher in Smith's study experience such autonomy while the teachers in the present study, who shared many of the same characteristicsm -high expectations of students, strong self-efficacy, and a desire for students to make sense of math for themselves- did not? Further research should examine teachers in various school settings in order to identify factors that enable educators to successfully implement reform even when faced with contexts that seem to inhibit other teachers.

Future research could also help to determine whether the differences observed between the kindergarten and second-grade teachers on the one hand and the fifth-grade teacher on the other hand are due to age, gender, teaching experience, the grade level taught, or to a combination of these or other factors. Indeed, the fifth-grade teacher's concern with students' performance on standardized tests aligns with findings associated with other fourth- through eighthgrade teachers in a quantitative belief-practices study conducted by Yurekli et al. (2020), whereas the early primary teachers, who did not express concern over performance on standardized tests, diverged from these findings.

\section{Limitations of the Study}

This study focuses on just three teachers from a single school district in the United States. Further research involving secondary teachers as well as teachers in different settings would expand our understanding of the beliefs and motivations that influence teachers' instructional choices from an EVT perspective. A 
limitation of the study is that it did not include classroom observations to corroborate the teachers' interview data. Cross Francis et al. (2015) note that self-reported data is problematic in teacher-beliefs research due to the potential for biased results. However, the study was specifically designed to address one of the primary concerns identified by the authors: "scales are constructed to assess mathematics beliefs while teachers' actions are often motivated by factors beyond beliefs about mathematics" (Cross Francis et al., 2015, p. 348). A primary goal of the study was to investigate the interaction between beliefs and motivations linked to school contexts, such as standardized testing and pacing guides, utilizing a framework that enabled factors other than just beliefs to emerge from the analysis. Teachers were in fact not directly asked about their beliefs; instead, their beliefs were surmised from the statements they made in the course of talking about their frustrations in trying to implement reform instruction within the constraints of their teaching contexts.

\section{Conclusions}

Although this research represents a single case study, the results raise important questions when contrasted with the larger-scale quantitative study conducted by Abrami et al. (2004). The present study confirms the utility of Expectancy Value Theory as a framework for examining teachers' beliefs and motivations and extends its application to qualitative approaches. Yet the study also challenges findings from Abrami et al. by suggesting that the cost component of the model, as opposed to expectancy of success, may weigh more heavily in teachers' instructional decisionmaking in certain contexts. Further research is needed to continue to explore the cost-benefit analyses that teachers make in determining whether, and to what extent, to adopt reform practices.

A major finding from this study is that teachers with a strong understanding of reform instruction and with personal beliefs supporting reform practices may nonetheless feel limited in their ability to implement these practices given the amount of content they must cover and the instructional time lost to testing. Many of today's teachers are operating in a "contradictory environment" in which they are being prodded to embrace reform instructional practices without the support of accompanying reforms in district-wide curriculum and assessment practices (Yurekli et al., 2020, p. 245). Researchers, policy makers, and school leaders wishing to foster a greater use of reform instruction would be wise to carefully analyze the policies, benchmarks, curricula, and testing requirements currently in place in public schools to look for ways to grant teachers more instructional time and freedom to hit key concepts at greater depth. The national standards in the United States, the Common Core State Standards for Mathematics, are built on a foundation of solid number sense; if that foundation is not in place, then expected outcomes associated with the standards will not be realized.

\section{Acknowledgements}

The author wishes to thank the teachers who participated in this study as well as Dr. Christine Rogers Stanton for her guidance during the research process. Dr. Natalie Bohlmann provided invaluable feedback on early drafts of this article.

\section{References}

Abrami, P. C., Poulsen, C., \& Chambers, B. (2004). Teacher motivation to implement an educational innovation: Factors differentiating users and non-users of cooperative learning. Educational Psychology, 24(2), 201-216. https:// doi.org/10.1080/0144341032000160146

Boaler, J. (2016). Mathematical mindsets: Unleashing students' potential through creative math, inspiring messages and innovative teaching. Jossey-Bass.

Boaler, J., \& Staples, M. (2008). Creating mathematical futures through an equitable teaching approach: The case of Railside school. Teachers College Record, 110(3), 608-645. Retrieved from http://www.tcrecord.org/Content. asp?Contentld=14590

Cooney, T. J. \& Shealy, B. E. (1997). On understanding the structure of teachers' beliefs and their relationship to change. In E. Fennema \& B. S. Nelson (Eds.) Mathematics teachers in transition (pp. 87-109). Lawrence Erlbaum Associates, Inc.

Cross Francis, D. I. (2015). Dispelling the notion of inconsistencies in teachers' mathematics beliefs and practices: A 3-year case study. Journal for Mathematics Teacher Education, 18, 173-201. https://doi.org/10.1007/s10857-014-9276-5

Cross Francis, D., Rapacki, L. \& Eker, A. (2015). The individual, the context, and practice: A review of the research on teachers' beliefs related to mathematics. In H. Fives \& M. G. Gill (Eds.), International handbook of research on teachers' beliefs (pp. 336-352). Routledge. 
Gill, M. G. \& Hoffman, B. (2009). Shared planning time: A novel context for studying teachers' discourse and beliefs about learning and instruction. Teachers College Record, 111, 12421273. Retrieved from https://www.tcrecord.org/ Content.asp?Contentld=15241

Goldsmith, L. T. \& Shifter, D. (1997). Understanding teachers in transition: Characteristics of a model for the development of mathematics teaching. In E. Fennema \& B. S. Nelson (Eds.) Mathematics teachers in transition (pp. 19-54). Lawrence Erlbaum Associates, Inc.

Hart, L. C. (2002). A four year follow-up study of teachers' beliefs after participating in a teacher enhancement project. In G. C. Leder, E. Pehkonen, \& G. Torner (Eds.), Beliefs: A hidden variable in mathematics education? (pp. 161176). Kluwer Academic Publishers.

Lloyd, G. (2002). Mathematics teachers' beliefs and experiences with innovative curriculum materials: The role of curriculum in teacher development. In G. C. Leder, E. Pehkonen, \& G. Torner (Eds.), Beliefs: A hidden variable in mathematics education? (pp. 149-159). Kluwer Academic Publishers.

Louie, N. L. (2017a). Supporting teachers' equityoriented learning and identities: A resourcecentered perspective. Teachers College Record, 119(2). Retrieved from http://www.tcrecord.org/ Content.asp?Contentld=21665

Louie, N. L. (2017b). The culture of exclusion in mathematics education and its persistence in equity-oriented teaching. Journal for Research in Mathematics Education, 48(5), 488-519.

National Council of Teachers of Mathematics. (1980). An agenda for action. Reston, VA.

National Council of Teachers of Mathematics. (1989). Curriculum and evaluation standards for school mathematics.

National Council of Teachers of Mathematics. (2000). Principles and standards for school mathematics.

National Council of Teachers of Mathematics. (2014). Principles to actions: Ensuring mathematical success for all.
Raymond, A. M. (1997). Inconsistency between a beginning elementary school teacher's mathematics beliefs and teaching practice. Journal for Research in Mathematics Education, 28(5), 550-576.

Ren, L. \& Smith, W. M. (2018). Teacher characteristics and contextual factors: Links to early primary teachers' mathematical beliefs and attitudes. Journal of Mathematics Teacher Education, 21, 321-350. https://doi.org/10.1007/s10857-017-93653

Rousseau, C. K. (2004). Shared beliefs, conflict, and a retreat from reform: The story of a professional community of high school mathematics. Teaching and Teacher Education, 20, 783-796. https://doi.org/10.1016/j.tate.2004.09.005

Smith, W. M. (2012). Exploring relationships among teacher change and uses of contexts. Mathematics Education Research Journal, 24, 301-321. https://doi.org/10.1007/s13394-012-00534

Stemhagen, K. (2011). Democracy and school math: Teacher belief-practice tensions and the problem of empirical research on educational aims. Democracy and Education, 19(2), 1-13. Available at https:// democracyeducationjournal.org/home/vol19/ iss $2 / 4$

Stipek, D. J., Givvin, K. B., Salmon, J. M., MacGyvers, V. L. (2001). Teachers' beliefs and practices related to mathematics instruction. Teaching and Teacher Education, 17, 213-226. https://doi. org/10.1016/S0742-051X(00)00052-4

Thompson, A. G. (1984). The relationship of teachers' conceptions of mathematics and mathematics teaching to instructional practice. Educational Studies in Mathematios, 15(2), 105-127.

Warfield, J., Wood, T., \& Lehman, J. D. (2005). Autonomy, beliefs and the learning of elementary mathematics teachers. Teaching and Teacher Education, 21, 439-456. Retrieved from https:// wWw.academia.edu/15558621/Autonomy_ beliefs_and_the_learning_of_elementary mathematics_teachers

Watt, H. M. G. \& Richardson, P. W. (2015). A motivational analysis of teachers' beliefs. In H. Fives \& M. G. Gill (Eds.), International handbook of research on teachers' beliefs (pp. 191-211). Routledge. 
Webel, C. \& Platt, D. (2015). The role of professional obligations in working to change one's teaching practices. Teaching and Teacher Education, 47, 204-217. https://doi.org/10.1016/j.tate.2015.01.007

Wigfield, A. \& Eccles, J. S. (2000). Expectancyvalue theory of achievement motivation. Contemporary Educational Psychology, 25, 6881. https://doi.org/10.1006/ceps.1999.1015

Wilkins, J. L. M. (2008). The relationship among elementary teachers' content knowledge, attitudes, beliefs, and practices. Journal of Mathematics Teacher Education, 11, 139-164. https://doi.org/10.1007/s10857-007-9068-2

Wilson, M. \& Cooney, T. J. (2002). Mathematics teacher change and development: The role of beliefs. In G. C. Leder, E. Pehkonen, \& G. Torner (Eds.), Beliefs: A hidden variable in mathematics education? (pp. 127-148). Kluwer Academic Publishers.

Windschitl, M. (2002). Framing constructivism in practice as the negotiation of dilemmas: An analysis of the conceptual, pedagogical, cultural, and political challenges facing teachers. Review of Educational Research, 72(2), 131-175. https://doi. org/10.3102/00346543072002131

Yurekli, B., Stein, M. K., Correnti, R., \& Kisa, Z. (2020). Teaching mathematics for conceptual understanding: Teachers' beliefs and practices and the role of constraints. Journal for Research in Mathematics Education, 51(2), 234-247. 